\title{
Proposta de gestão de resíduos de produtos químicos gerados nas unidades públicas de saúde no município de Viamão (RS)
}

\author{
Cláudia Rejane Silva \\ Discente. Instituto Federal do Rio Grande do Sul (IFRS) \\ (clau.r.silva@hotmail.com) \\ Magali da Silva Rodrigues \\ Docente. Instituto Federal do Rio Grande do Sul (IFRS) \\ (magali.rodrigues@poa.ifrs.edu.br)
}

\begin{abstract}
Resumo: Os resíduos de produtos químicos gerados nas unidades públicas de saúde de diversos municípios têm sido sistematicamente descartados na rede de esgotos, em decorrência de não haver um plano de gestão que os contemple. Este trabalho teve como objetivo apresentar uma proposta de gestão de resíduos químicos no município de Viamão (RS). A metodologia empregada para o seu desenvolvimento foi quantitativa, através de diagnóstico, no qual foram identificados os produtos químicos utilizados nas unidades de saúde e distribuídos recipientes para a coleta destes; foi determinado o volume dos resíduos gerados no período de uma semana e estimada a extrapolação destes resíduos para um mês e para um ano. $\mathrm{Na}$ análise dos dados coletados, os resíduos químicos foram classificados segundo a Resolução RDC ANVISA 306/04 e a Norma ABNT NBR 10004:2004, que classificam os resíduos a partir de suas características de periculosidade e riscos. Os resultados apontaram importante potencial de periculosidade e riscos ambientais dos resíduos. Desta forma, foram elaborados dois documentos de gestão, que visam organizar e padronizar o manejo interno e externo dos resíduos químicos, e que servirão de base para capacitação dos servidores nas unidades públicas de saúde, evitando, assim, o seu descarte inadequado.
\end{abstract}

Palavras-chave: Resíduos químicos; Unidades públicas de saúde; Gestão de resíduos químicos.

\section{A proposal of managing the chemical residues generated in the public health units in the city of Viamão (RS)}

\begin{abstract}
Residues of chemicals generated in the public health units of several municipalities have been systematically discarded in the sewage network as a result of the absence of a management plan that contemplates them. This study aimed to present a proposal for chemical waste management in the municipality of Viamão / RS. The methodology used for its development was quantitative, through a diagnosis in which the chemical products used in the health units were identified and containers distributed to collect them; the volume of waste generated in a period of one week was estimated and the extrapolation of this waste to one month and one year was estimated. Analysis of data collected from chemical residues were classified according to ANVISA Resolution RDC 306/04 and ABNT NBR 10004: 2004 which classify the waste, their dangerousness and risk characteristics. The results indicated the hazardous potential and environmental risks of the residues. In this way, two management documents were elaborated to organize and standardize the internal and external management of chemical residues, which will serve as a basis for the training of the employees in the public health units, thus avoiding their inappropriate disposal.
\end{abstract}

Keywords: Chemical wastes; Public health units; Chemical waste management. 


\section{INTRODUÇÃO}

Segundo Daniel (2013), as ações do homem sobre a natureza, seja pela supressão de vegetação, ocupação do solo ou lançamento de resíduos sem tratamento no ambiente, além de danos ambientais, são uma questão de saúde pública. Para o autor, o lançamento sem tratamento de resíduos sólidos, líquidos ou gasosos leva à contaminação do ar, do solo e das águas superficial e subterrânea e que, dependendo do grau de exposição e concentração dos poluentes, os efeitos prejudiciais à saúde humana podem ser agudos, crônicos ou resultar em óbito.

A Lei Federal no 12.305 (BRASIL, 2010) institui a Política Nacional de Resíduos Sólidos (PNRS), e define resíduos sólidos como:

Material, substância, objeto ou bem descartado resultante de atividades humanas em sociedade, a cuja destinação final se procede, se propõe proceder ou se está obrigado a proceder, nos estados sólido ou semissólido, bem como gases contidos em recipientes e líquidos cujas particularidades tornem inviável o seu lançamento na rede pública de esgotos ou em corpos d'água, ou exijam para isso soluções técnicas ou economicamente inviáveis em face da melhor tecnologia disponível. (BRASIL, 2010).

O art. 9 da PNRS prevê que na gestão e gerenciamento de resíduos sólidos é necessário que sejam observadas como prioridade: não geração, redução, utilização, reciclagem e tratamento destes resíduos e disposição final ambientalmente adequada dos rejeitos. A Política Nacional de Resíduos Sólidos foi regulamentada pelo Decreto oㅜ 7.404 , de 23 de dezembro de 2010, que estabelece normas para a sua aplicação e, em seu art. $5^{\circ}$, define que "os fabricantes, importadores, distribuidores, comerciantes, consumidores e titulares dos serviços públicos de limpeza urbana e de manejo de resíduos sólidos são responsáveis pelo ciclo de vida dos produtos", definindo também no seu parágrafo único que "a responsabilidade compartilhada será implementada de forma individualizada e encadeada" (BRASIL, 2010).

A referida Lei, em seu art. 13, classifica os resíduos sólidos quanto a sua origem e tem os Resíduos de Serviços de Saúde (RSS) como um de seus itens. O gerenciamento interno dos RSS é regulamentado pela Agência Nacional de Vigilância Sanitária (ANVISA), vinculada ao Ministério da Saúde, através da Resolução da Diretiva Colegiada (RDC) no 306/04, de 07 de dezembro de 2004, que dispõe sobre o Regulamento Técnico para o gerenciamento destes resíduos a partir de sua classificação que é definida nesta resolução, e também no Conselho 
Nacional do Meio Ambiente (CONAMA), vinculado ao Ministério do Meio Ambiente, por meio da Resolução no 358/05, de 29 de abril de 2005, que prevê um gerenciamento externo destes resíduos, ou seja, dispõe sobre o tratamento e a disposição final dos RSS. Esta resolução, em seu art.1ํㅡ, tem a seguinte definição para Resíduos de Serviços de Saúde:

Todos aqueles relacionados com o atendimento à saúde humana ou animal, inclusive os serviços de assistência domiciliar e de trabalhos de campo; laboratórios analíticos de produtos para saúde; necrotérios, funerárias e serviços onde se realizem atividades de embalsamamento (tanatopraxia e somatoconservação); serviços de medicina legal; drogarias e farmácias inclusive as de manipulação; estabelecimentos de ensino e pesquisa na área de saúde; centros de controle de zoonoses; distribuidores de produtos farmacêuticos; importadores, distribuidores e produtores de materiais e controles para diagnóstico in vitro [grifo do autor]; unidades móveis de atendimento à saúde; serviços de acupuntura; serviços de tatuagem, entre outros similares. (BRASIL, 2005).

Com vistas a prevenir acidentes, preservando a saúde pública e o meio ambiente através do correto manejo, desde a sua geração até a sua destinação final, reduzindo acidentes ocupacionais e promovendo outros benefícios, os Resíduos de Serviços de Saúde são classificados pela Resolução da Diretiva Colegiada (RDC) ANVISA $n^{\circ}$ 306/2004. Neste sentido, estes resíduos são classificados em cinco grupos de $\mathrm{A}$ a $\mathrm{D}$, de acordo com potencial de risco como: Biológico, Físico, Químico, Ergonômico, Risco de Acidente ou Risco Pela Falta de Conforto e Higiene.

O Grupo A compreende resíduos potencialmente infectantes, ou seja, resíduos com a possível presença de agentes biológicos que, por suas características, podem apresentar risco de infecção. O Grupo B compreende resíduos que contêm substâncias químicas que podem apresentar risco à saúde pública ou ao meio ambiente, dependendo de suas características de inflamabilidade, corrosividade, reatividade e toxicidade, conforme classificação da Associação Brasileira de Normas Técnicas (ABNT) NBR 10.004:2004. O Grupo C compreende resíduos radioativos, ou seja, quaisquer materiais resultantes de atividades humanas que contenham radionuclídeos em quantidades superiores aos limites de isenção especificados nas normas do Conselho Nacional de Energia Nuclear (CNEN), e para os quais a reutilização é imprópria ou não prevista. O Grupo D compreende resíduos comuns que não apresentem risco biológico, químico ou radiológico à saúde ou ao meio ambiente, podendo ser equiparados aos resíduos 
domiciliares. O Grupo E compreende resíduos perfurocortantes ou escarificantes, tais como: lâminas de barbear, agulhas, escalpes, ampolas de vidro, brocas, pontas diamantadas, lâminas de bisturi, lancetas, tubos capilares, lâminas e lamínulas, espátulas e todos os utensílios de vidro quebrados no laboratório (pipetas, tubos de coleta sanguínea) e outros similares (ABNT,2004).

Uma das determinações da fiscalização do Conselho Regional de Enfermagem - COREN/RS é de que ao final de cada semana todas as almotolias (frascos plásticos onde são acondicionados os produtos químicos utilizados no atendimento aos pacientes), conforme apresentado na Figura 1, devem ser esvaziadas, lavadas e preenchidas novamente no início da semana seguinte. Os produtos químicos referidos são utilizados nos seguintes procedimentos: curativos, assepsia da pele para aplicação de medicamentos intramusculares ou intravenosos, aferição de batimentos cardíacos em fetos, higienização das mãos, esterilização de materiais e assepsia da pele para pequenos procedimentos cirúrgicos. Cabe ressaltar que todos os produtos citados obedecem ao estabelecido pelo COREN/RS, quanto ao prazo de validade para a utilização nos atendimentos realizados. Os produtos químicos utilizados nas unidades de saúde são: álcool diluído a $70 \%$ $\left(\mathrm{C}_{2} \mathrm{H}_{6} \mathrm{O}\right)$, iodofor $\left(\mathrm{C}_{6} \mathrm{H}_{9} \mathrm{NO}\right)$, vaselina líquida e sólida (fórmula não aplicável), gel condutor $\left(\mathrm{CH}_{2}-\mathrm{CH}(\mathrm{COOH})\right.$, ácido peracético $\left(\mathrm{C}_{2} \mathrm{H}_{4} \mathrm{O}_{3}\right)$. Os resíduos destes produtos não possuem uma gestão adequada, pois os mesmos são descartados na rede pública de esgoto.

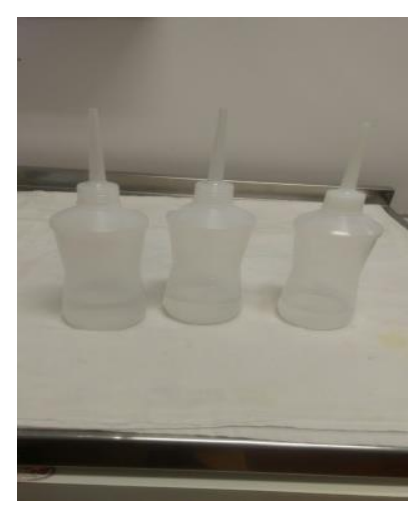

Figura 1: Almotolias. Fonte: Autora (2016)

Os resíduos descartados semanalmente das almotolias nas unidades de saúde se enquadram no grupo B (químicos), de acordo com RDC ANVISA 306/04 e são classificados, segundo a norma ABNT NBR 10.004:2004 como Resíduos Classe 
I, denominados como perigosos. Os mesmos são classificados assim em função de suas propriedades físicas, químicas ou biológicas, que podem apresentar riscos à saúde e ao meio ambiente e são caracterizados por possuírem uma ou mais das seguintes propriedades: inflamabilidade, corrosividade, reatividade, toxicidade e patogenecidade. As alternativas de tratamento para resíduos com estas características estão contidas na Ficha de Informações de Segurança de Produtos Químicos - FISPQ, conforme a norma ABNT NBR 14725:2001, Decreto/PR 2657/98.

Este trabalho teve como objetivo elaborar uma proposta de gestão, através de documentos que orientem o gerenciamento interno e externo dos resíduos químicos, gerados nas unidades de saúde, que estão sob a responsabilidade da gestão municipal. Teve como base para seu desenvolvimento as etapas de diagnóstico, que buscou a estimativa de volume dos resíduos gerados; determinação das características dos resíduos e principais impactos ao meio ambiente, além da classificação, de acordo com as normas e resoluções ambientais vigentes. A proposta de gestão visou a capacitação dos técnicos para a adoção de práticas adequadas de manejo, com vistas à destinação correta dos resíduos gerados nas unidades, além de atender ao que está previsto na Lei Federal no 12.305/10, na Resolução CONAMA no 358/05 e na Resolução RDC ANVISA no 306/04, contribuindo, assim, para uma melhor qualidade ambiental e de saúde pública.

\section{OBJETIVOS}

\subsection{Objetivo Geral}

Elaborar os documentos Procedimento Operacional Padrão (POP) para a gestão dos resíduos químicos gerados nas Unidades de Saúde do Município de Viamão (RS).

\subsection{Objetivos específicos}

- Identificar os resíduos químicos gerados nas unidades de saúde do município de Viamão (RS); 
- Determinar o volume de resíduos químicos gerados nas unidades;

- Classificar os resíduos químicos gerados, segundo a norma ABNT NBR 10.004:2004 e RDC ANVISA 306/04.

\section{MATERIAIS E MÉTODOS}

A pesquisa que resultou neste trabalho foi desenvolvida em aproximadamente seis (6) meses, tendo iniciado no mês de junho de 2016, quando os primeiros contatos com a Secretaria de Saúde de Viamão (RS) foram realizados, para a apresentação do projeto. A metodologia empregada para o desenvolvimento deste trabalho foi quantitativa, através de diagnóstico, que foi desenvolvido em três etapas. A primeira etapa foi composta por entrevistas com as equipes de enfermagem, na qual identificaram-se os produtos químicos utilizados. Essa etapa contou também com a distribuição de recipientes para coleta dos respectivos resíduos gerados. A segunda etapa constituiu-se pela determinação dos volumes dos resíduos químicos gerados. A terceira etapa contou com a classificação dos resíduos químicos, segundo a norma ABNT NBR 10.004:2004 e Resolução RDC ANVISA 306/04, que determinam as características de periculosidade e risco dos resíduos.

A distribuição dos recipientes ocorreu nas dezesseis (16) Unidades de Saúde da Atenção Básica e uma (1) Unidade de Pronto Atendimento (UPA) existentes no município. Para que o diagnóstico tivesse êxito, as equipes de enfermagem receberam informações acerca dos objetivos da pesquisa, para que assim compreendessem a importância de sua colaboração na coleta dos resíduos. Os recipientes distribuídos nas unidades de saúde foram devidamente identificados com o nome do resíduo químico a ser coletado (Figura 2). Desta forma, o servidor responsável pela lavagem das almotolias realizou a coleta dos resíduos gerados nos respectivos recipientes, pelo período de uma (1) semana. Os mesmos foram recolhidos na semana seguinte.

Posteriormente, o volume dos resíduos coletados foi medido, utilizando-se um copo medida, com capacidade e graduação de 1.000 mililitros $(\mathrm{ml})$, e uma seringa de 20 mililitros (ml). Com isso, foi determinado o volume dos diferentes resíduos de produtos químicos, gerados semanalmente nas unidades de saúde do município de Viamão/RS. Após a determinação do volume de resíduos químicos gerados em uma 
semana, foi realizada uma estimativa mensal e anual da geração, através da divisão do volume encontrado por sete (7) e seu resultado multiplicado por trinta (30) dias e este resultado multiplicado por doze (12) meses, com vistas à extrapolação da geração.

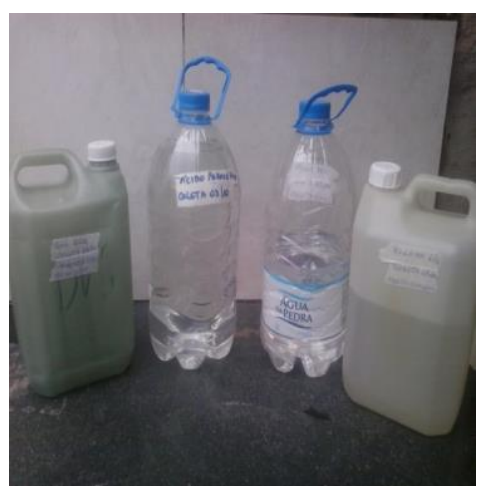

Figura 2: Recipientes onde foram coletados os resíduos. Fonte: Autora (2016).

$\mathrm{Na}$ etapa seguinte, foi realizada a classificação dos resíduos encontrados, conforme a Resolução RDC ANVISA n 306/04, de 07 de dezembro de 2004, que dispõe sobre o Regulamento Técnico para o gerenciamento dos resíduos do serviço de saúde e, também, conforme a Norma ABNT NBR 10.004:2004, que classifica os resíduos em razão de suas propriedades físicas, químicas ou biológicas e que podem apresentar riscos à saúde e ao meio ambiente e são caracterizados desta forma por possuírem uma ou mais das seguintes propriedades: inflamabilidade, corrosividade, reatividade, toxicidade e patogenecidade.

\section{RESULTADOS E DISCUSSÃO}

Os resíduos identificados no diagnóstico foram: ácido peracético, água oxigenada, álcool a 70\%, álcool gel, tintura de benjoim, gel condutor, sabonete líquido e vaselina líquida. O Quadro 1 apresenta o resultado da coleta de uma semana, a estimativa mensal e anual da geração de resíduos, bem como as suas características de periculosidade e riscos definidos pela ficha FISPQ, conforme norma ABNT NBR 14725:2001 e Decreto/PR 2657/98, sua classificação quanto à periculosidade e riscos de acordo com a norma NBR 10.004:2004 e sua classificação quanto ao potencial de risco, segundo a Resolução da Diretiva Colegiada RDC ANVISA N³06/2004. 
Quadro 1: Volume de resíduos gerados em uma semana, estimativa mensal e anual dos resíduos gerados, sua classificação e características.

\begin{tabular}{|c|c|c|c|c|c|c|}
\hline PRODUTO & $\begin{array}{l}\text { VOLUME } \\
\text { DE } \\
\text { RESÍDUOS } \\
\text { DE UMA } \\
\text { SEMANA }\end{array}$ & $\begin{array}{c}\text { ESTIMATIVA } \\
\text { DE VOLUME } \\
\text { DE } \\
\text { RESÍDUOS } \\
\text { EM UM MÊS } \\
\end{array}$ & $\begin{array}{c}\text { ESTIMATIVA } \\
\text { DE VOLUME } \\
\text { DE } \\
\text { RESÍDUOS } \\
\text { EM UM ANO } \\
\end{array}$ & $\begin{array}{c}\text { CARACTERÍSTICAS } \\
\text { DE } \\
\text { PERICULOSIDADE } \\
\text { E RISCOS }\end{array}$ & $\begin{array}{l}\text { NBR 10004:2004 } \\
\text { CLASSIFICAÇÃO } \\
\text { QUANTO Ã } \\
\text { PERICULOSIDADE }\end{array}$ & $\begin{array}{c}\text { RDC ANVISA } \\
306 / 2004 \\
\text { CLASSIFICAÇÃO } \\
\text { QUANTO AO } \\
\text { POTENCIAL DE } \\
\text { RISCO }\end{array}$ \\
\hline $\begin{array}{c}\text { Ácido } \\
\text { Peracético }\end{array}$ & $7,80 \mathrm{~L}$ & $33,42 \mathrm{~L}$ & $401,14 \mathrm{~L}$ & $\begin{array}{l}\text { Inflamabilidade, } \\
\text { toxicidade, } \\
\text { corrosividade }\end{array}$ & \multirow{8}{*}{$\begin{array}{c}\text { CLASSE I } \\
\text { (PERIGOSOS) }\end{array}$} & \multirow{8}{*}{$\begin{array}{l}\text { GRUPO B } \\
\text { (QUÍMICOS) }\end{array}$} \\
\hline $\begin{array}{c}\text { Água } \\
\text { Oxigenada }\end{array}$ & $0,35 \mathrm{~L}$ & $1,50 \mathrm{~L}$ & $18,00 \mathrm{~L}$ & $\begin{array}{l}\text { Toxicidade, } \\
\text { reatividade }\end{array}$ & & \\
\hline Álcool a 70\% & $2,70 \mathrm{~L}$ & $11,57 \mathrm{~L}$ & $138,85 \mathrm{~L}$ & $\begin{array}{l}\text { Toxicidade, } \\
\text { reatividade, } \\
\text { inflamabilidade }\end{array}$ & & \\
\hline Álcool Gel & $1,05 \mathrm{~L}$ & $4,50 \mathrm{~L}$ & $54,00 \mathrm{~L}$ & $\begin{array}{l}\text { Inflamabilidade, } \\
\text { toxicidade }\end{array}$ & & \\
\hline Gel Condutor & $0,22 \mathrm{~L}$ & $0,94 \mathrm{~L}$ & $11,31 \mathrm{~L}$ & $\begin{array}{l}\text { Inflamabilidade, } \\
\text { toxicidade, } \\
\text { reatividade }\end{array}$ & & \\
\hline $\begin{array}{l}\text { Sabonete } \\
\text { líquido }\end{array}$ & $4,60 \mathrm{~L}$ & $19,71 \mathrm{~L}$ & $236,57 \mathrm{~L}$ & $\begin{array}{l}\text { Risco leve à saúde } \\
\text { humana se em } \\
\text { contato com } \\
\text { mucosas }\end{array}$ & & \\
\hline $\begin{array}{l}\text { Tintura de } \\
\text { Benjoim }\end{array}$ & $0,10 \mathrm{~L}$ & $0,42 \mathrm{~L}$ & $5,14 \mathrm{~L}$ & $\begin{array}{l}\text { Reatividade, risco } \\
\text { leve para a saúde } \\
\text { humana. }\end{array}$ & & \\
\hline $\begin{array}{l}\text { Vaselina } \\
\text { Líquida }\end{array}$ & $3,15 \mathrm{~L}$ & $13,50 \mathrm{~L}$ & $162,00 \mathrm{~L}$ & $\begin{array}{l}\text { Toxicidade, } \\
\text { inflamabilidade e } \\
\text { reatividade. }\end{array}$ & & \\
\hline
\end{tabular}

Fonte: Autora (2016).

Ressalta-se que não foi possível realizar a medição de algumas substâncias em algumas das unidades de saúde, devido ao diagnóstico ter sido realizado em período que não correspondia ao seu descarte ou em virtude do produto estar em falta na unidade de saúde. Como exemplo, cita-se o ácido peracético, o qual apresenta validade superior aos demais produtos, cerca de um (1) mês. É importante destacar que a falta de transporte disponível na data prevista para a coleta impossibilitou o recolhimento dos resíduos químicos de duas unidades de saúde. Desta forma, o diagnóstico não inclui os resíduos destas unidades.

Para compreender melhor a realidade referente ao manejo dos resíduos sólidos gerados na cidade de Viamão (RS), foi realizada busca no site da Prefeitura, onde encontrou-se a publicação oficial, LEI MUNICIPAL oㅜ 4.374/2015 (VIAMÃO, 2015), que institui a Política Municipal de Saneamento Básico e de Resíduos Sólidos Urbanos do município de Viamão (RS) (PSBRSU). A pesquisa contou, também, pela busca do documento Plano de Gerenciamento de Resíduos de Serviços de Saúde (PGRSS). No entanto, seu conteúdo estava indisponível, pois o mesmo encontravase em revisão para atualização. O contrato firmado entre a Prefeitura de Viamão 
(RS) e a Empresa Urban Serviços e Transportes Ltda., empresa responsável pelo recolhimento dos Resíduos de Serviços de Saúde, também foi avaliado. No contrato (no 113/2014), cláusula segunda - item III, estão previstos os serviços de coleta, transporte, acondicionamento, tratamento e destinação final dos resíduos Sólidos de Serviços de Saúde (RSSS), classificados de acordo com o Anexo I da Resolução CONAMA n' 358/2005, como grupos "A", "B", "C" e "E", provenientes dos estabelecimentos da rede pública municipal de Unidades Básicas de Saúde e controle de Zoonoses, estimados em $13.500 \mathrm{~kg}$ (treze mil e quinhentos quilogramas por mês).

A partir das práticas observadas nas unidades de saúde e da documentação analisada, fica evidente que, apesar da existência da Política de Saneamento Básico e Resíduos Sólidos Urbanos (PSBRSU) e do contrato com a empresa Urban, o município de Viamão (RS) ainda não possui uma gestão adequada para os resíduos gerados. A falta de gestão fica evidente através do descarte dos conteúdos das almotolias nas unidades de saúde, sendo estes resíduos sistematicamente descartados na rede pública de esgoto. Nesse sentido, com vistas a atender ao objetivo geral do trabalho, foram elaborados os documentos de Procedimento Operacional Padrão (POP), destinado a Gestão Interna dos Resíduos Químicos e Procedimento Operacional Padrão (POP), destinado a Gestão de Destinação Final dos Resíduos Químicos, conforme apresentado nas Figuras 3, 4, 5 e 6.

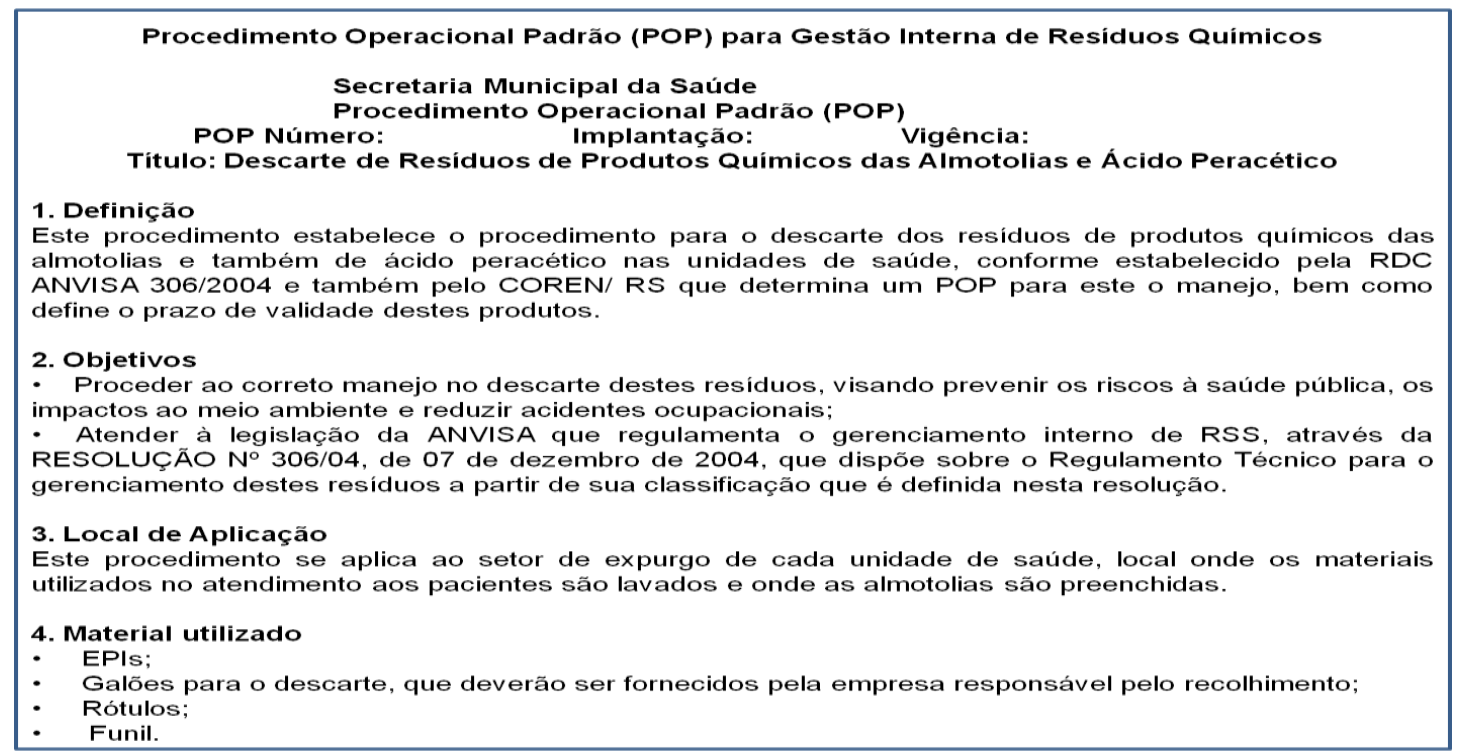

Figura 3: Página 1 POP-Gestão Interna 


\section{Método}

Rotular os galōes de acordo com o produto químico a ser coletado; colocar os EPIs; despejar os produtos em cada galão especificado no rótulo utilizando o funil, tampar o galão e guardá-lo dentro de um balcão ou abaixo de bancada de forma que fique protegido até a próxima coleta ou até que seja recolhido pela empresa responsável pelo recolhimento, o que deverá ser realizado uma (1) vez por mês.

OBS: A coleta deverá ser realizada no período máximo de um (1) mês.

6. Responsabilidade

Toda a equipe de enfermagem de acordo com a escala de serviço. Também é previsto neste POP, a permanente capacitação das equipes de enfermagem para a implementação deste procedimento, no sentido de que as ações sejam sistematizadas, sendo pauta nas reuniões das equipes.

REFEREANCIAS

ASSOCIACÄO BRASILEIRA DE NORMAS TÉCNICAS (ABNT). NBR 12.235:1992- Armazenamentos de residuos sólidos perigosos. Rio de Janeiro, 1992

ASSOCIAÇÃO BRASILEIRA DE NORMAS TÉCNICAS - ABNT. NBR 10004 - Residuos sólidos -classificação. Rio de Janeiro: ABNT, 2004

BRASIL. Lei $n^{\circ}$ 12.305, de 2 de agosto de 2010. Dispõe sobre a Politica Nacional de Residuos Sólidos, altera a Lei $n^{\circ} 9.605$ de 12 de fevereiro de 1998; e dá outras providências. Diário Oficial da União, Brasilia, DF, 2 ago. 2010.

BRASIL. Ministério do Meio Ambiente. RESOLUÇÃO No 358 DE 29 DE ABRIL DE 2005 (CONAMA). Dispõe sobre o tratamento e a disposição final dos residuos de serviços de saúde.

BRASIL. Ministério da Saúde. RESOLUÇÃO No 306/04 de 07 de dezembro de 2004 (ANVISA). Dispöe sobre o Regulamento Técnico para o gerenciamento dos Residuos de Serviços de Saúde e dá outras providências.

BRASIL. Ministério do Trabalho. Gabinete do Ministro. Portaria n³214, de 8 de junho de 1978. Aprova as Normas Regulamentadoras-NR- do capitulo V, do titulo II, da Consolidaçăo das Leis do Trabalho, Brasilia, 06 de julho de 1978.

Figura 4: Página 2- POP Gestão Interna.

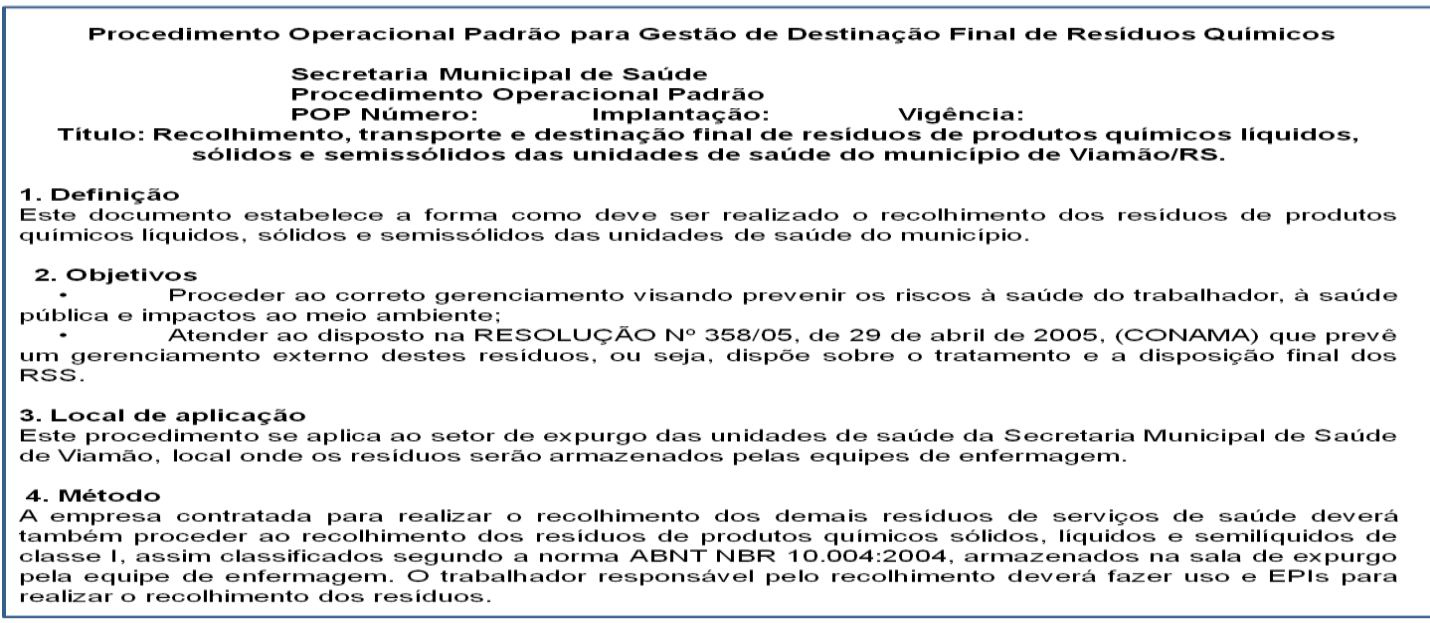

Figura 5: Página 1- POP Gestão de Destinação Final.

OBS. O recolhimento destes resíduos deverá ser efetuado no prazo máximo de um (1) mês em virtude de suas características de periculosidade. Para este procedimento deverá ser observado que imediatamente após completar um (1) mês da coleta realizada pela equipe de enfermagem, a empresa responsáve deverá realizar o recolhimento, sob pena de multa.

5. Responsabilidade

Toda a equipe de enfermagem, de acordo com a escala de serviço, e os funcionários da empresa contratada, sob a supervisão do(a) enfermeiro(a).

OBS: Sugere-se também que seja desenvolvida pela equipe de enfermagem uma planilha onde fiquem apontados os dias previstos para o recolhimento dos resíduos, os quais deverão ser checados para que, desta forma, as açōes relativas a este procedimento possam ser monitoradas, permitindo, assim, a veríficação da eficácia da nova sistemática.

\section{REFERENCIAS}

ASSOCIACÃO BRASILEIRA DE NORMAS TÉCNICAS (ABNT). NBR 12.235:1992- Armazenamentos de residuos sólidos perigosos. Rio de Janeiro, 1992.

ASSOCIAÇÃO BRASILEIRA DE NORMAS TÉCNICAS - ABNT. NBR 10004 - Resíduos sólidos classificação. Rio de Janeiro: ABNT, 2004

BRASIL. Lei $n^{\circ} 12.305$, de 2 de agosto de 2010. Dispỏe sobre a Política Nacional de Resíduos Sólidos, altera a Lei no 9.605, de 12 de fevereiro de 1998; e dá outras providências. Diário Oficial da União, Brasília. DF, 2 ago. 2010

BRASIL. Ministério do Meio Ambiente. RESOLUÇĀO No 358 DE 29 DE ABRIL DE 2005 (CONAMA). Dispöe sobre o tratamento e a disposiçăo final dos residuos de serviços de saúde.

BRASIL. Ministério do Trabalho. Gabinete do Ministro. Portaria n³214, de 8 de junho de 1978. Aprova as Normas Regulamentadoras - NR- do capítulo $V$, do título II, da Consolidação das Leis do Trabalho, Brasília, 06 de julho de 1978.

Figura 6: Página 2- POP Gestão de Destinação Final. 
Os POPs foram elaborados pensando na realidade das atribuições demandadas para as equipes de enfermagem. Neste sentido, estes procedimentos são de fácil compreensão e aplicação, tendo em vista que são poucos itens a serem observados e que os materiais que compõem a proposta de gestão são basicamente aqueles já utilizados pelas equipes, excetuando-se os galões e o funil. Tendo em vista que, parte deste procedimento já é rotina das equipes, quando as almotolias são lavadas (higienizadas), o ponto em que o novo procedimento irá se diferenciar será na destinação dos resíduos. A partir dos novos procedimentos (POPs), os resíduos serão descartados nos galões e não mais na rede de esgoto, para posteriormente serem recolhidos pela empresa responsável pela coleta. Pretendese que neste novo projeto de gestão seja incluída, também, a capacitação das equipes, com um calendário para a nova rotina ser realizada. Os novos procedimentos deverão ser apresentados a partir das reuniões gerais realizadas nos locais de trabalho, bem como através de reuniões de enfermagem, onde serão discutidas as dificuldades ou facilidades encontradas na sua implementação. Oportunamente, serão discutidas com os técnicos necessidades de atualização dos procedimentos implementados.

\section{CONSIDERAÇÕES FINAIS}

O resultado obtido com o diagnóstico dos resíduos de produtos químicos gerados, oriundos das unidades de saúde, revelou características de periculosidade e de riscos, tanto do ponto de vista de saúde humana, quanto de danos ambientais. Diante do cenário atual, fica clara e evidente a necessidade da implementação de ações efetivas para a gestão dos resíduos. O objetivo primordial deste trabalho, que visou à elaboração de documentos de gestão para os resíduos citados, buscou colaborar para a efetivação destas ações, através de ferramentas simples e de fácil aplicação. Projeta-se, neste sentido, utilizar ferramentas já existentes na atual gestão, como a empresa Urban Serviços e Transportes Ltda., que presta serviços na área de Resíduos de Serviços de Saúde no município de Viamão (RS) para que, desta forma, o novo manejo dos resíduos de produtos químicos de serviços de saúde possa ser implementado em conformidade ao o que preconizam a RDC 306/2004 (ANVISA) e a RESOLUÇÃO 358/2005 (CONAMA). 
Espera-se que os Procedimentos Operacionais Padrão (POPs), elaborados para a gestão dos resíduos químicos gerados nas unidades de saúde do Município de Viamão (RS), possam ser implementados pela Secretaria Municipal de Saúde, independentemente do documento "Plano de Gerenciamento de Resíduos de Serviços de Saúde (PGRSS)", o qual está em revisão e atualização. Além disso, espera-se, também, que a partir da aprovação do novo PGRSS, os procedimentos desenvolvidos nesta pesquisa possam ser anexados. Com isso, o município contribuirá para a melhoria da qualidade de vida da população, através da diminuição dos riscos para saúde dos trabalhadores, dos riscos para a saúde pública e também diminuição dos danos ao meio ambiente.

\section{REFERÊNCIAS}

ASSOCIAÇÃO BRASILEIRA DE NORMAS TÉCNICAS - ABNT. NBR 10004 - Resíduos sólidos - classificação. Rio de Janeiro: ABNT, 2004.

ASSOCIAÇÃO BRASILEIRA DE NORMAS TÉCNICAS - ABNT. NBR 14725:2001 - Ficha de Informações de Segurança de Produtos Químicos - FISPQ. Rio de Janeiro: ABNT, 2001.

BRASIL. Lei no 12.305, de 2 de agosto de 2010. Dispõe sobre a Política Nacional de Resíduos Sólidos, altera a Lei no 9.605, de 12 de fevereiro de 1998; e dá outras providências. Diário Oficial da União, Brasília, DF, 2 ago. 2010.

BRASIL. Ministério do Meio Ambiente. RESOLUÇÃO no 358, DE 29 DE ABRIL DE 2005 (CONAMA). Dispõe sobre o tratamento e a disposição final dos resíduos dos serviços de saúde e dá outras providências.

BRASIL. Ministério da Saúde. RESOLUÇÃO no 306/04, de 07 de dezembro de 2004 (ANVISA). Dispõe sobre o regulamento técnico para o gerenciamento de resíduos de serviços de saúde.

DANIEL, L. A. Meio ambiente e saúde pública. In.: ASHBY, M. F. Engenharia Ambiental: conceitos, tecnologias e gestão. Rio de Janeiro, Elsevier, 2013, p.96- 118.

VIAMÃO. Câmara Municipal. Lei Municipal no 4.374/2015. Política Municipal de Saneamento Básico e de Resíduos Sólidos Urbanos de VIAMÃO/RS. 2015. Disponível em: <http://www.viamao.rs.gov.br/files/POLTICA_MUNICIPAL_DE_SANEAMENTO_BSICO _E_DE_RESDUOS_SLIDOS_URBANOS.pdf >. Acesso em: 15 out. 2016. 